\title{
The Effect of the Closed-Loop Control System on Blood Glucose Control With Exercise: A Critically Appraised Topic
}

\author{
Melanie A. Mason, DAT, LAT, ATC, ${ }^{1}$ Anne C. Russ, PhD, LAT, ATC, ${ }^{2}$ Ryan T. Tierney, PhD, LAT, ATC, ${ }^{2}$ \\ and Jamie L. Mansell, PhD, LAT, ATC ${ }^{2}$ \\ ${ }^{1}$ Graceland University; ${ }^{2}$ Temple University
}

\begin{abstract}
Context: Exercise can cause fluctuations in blood glucose control in type 1 diabetics. For athletes with type 1 diabetes, maintenance of blood glucose within an ideal range may be difficult. Objective: To determine, in individuals with type 1 diabetes, the effectiveness of the closed loop control system versus the open loop control system in keeping blood glucose levels in the ideal range with exercise. Data Sources: A search of PubMed was conducted in June of 2020 using the Boolean phrases: (closed loop control system OR artificial pancreas) AND type 1 diabetes AND exercise AND ideal range AND adolescents, artificial pancreas AND glucose prediction AND exercise. Study Selection: Titles were reviewed for relevance, the abstract was then assessed for applicability, and finally the full text was examined. Articles were included that examined the percent of time in the ideal blood glucose range when exercise occurred during that day. Articles were excluded that didn't compare the closed loop and open loop control systems and articles that did not involve exercise. Data Extraction: The PEDro scale was used to determine the methodological quality of the included studies. The measure addressed was the percent of time in the ideal blood glucose range of 70-180 mg/dL. 95\% Confidence Intervals and Cohen's D were calculated for each article. Data Synthesis: The search yielded 268 articles and 3 were selected for inclusion. The two randomized controlled trials scored 9/10 on the PEDro scale and the randomized two-arm crossover clinical trial scored $9 / 10$ on the PEDro scale. Percent time spent in the ideal blood glucose range when exercise was performed was significantly higher in the closed loop group versus the open loop group in each of the three studies. In one randomized control trial, mean time in the ideal range was $71.3 \%(S D=17.6,95 \% \mathrm{CI}=62.5,80.10)$ in the closed loop group versus $64.7 \%(S D=13.3,95 \% \mathrm{CI}=58.1-71.4)$ in the open loop group. Cohen's $\mathrm{D}$ was 0.4 . In the second randomized control trial, mean time in the ideal range was $73.5 \%(S D=8.4,95 \% \mathrm{CI}=70.1,76.9)$ for the closed loop group versus $50 \%$ $(S D=26.8,95 \% \mathrm{CI}=39.1,60.9)$. Cohen's $\mathrm{D}$ was 1.2. The two-arm crossover clinical trial resulted in a mean time in target range of $84.1 \%(S D=11.5,95 \% \mathrm{CI}=79.0,89.2)$ in the closed loop group versus $68.7 \%(S D=13.9,95 \% \mathrm{CI}=62.5,74.9)$ in the open loop group. Cohen's D was 1.2. Conclusions: For adolescents with type 1 diabetes who exercise, the closed loop control system maintains blood glucose levels in the ideal range for a longer percent of time versus an open loop system. Each patient should be evaluated on a case-by-case basis with his/her healthcare team. Future research should examine the closed loop control system on specific energy systems.
\end{abstract}

Keywords: adolescents, artificial pancreas, diabetes

\section{Clinical Scenario}

According to the 2020 National Diabetes Statistics Report, approximately 187,000 children and adolescents in the United States have Type 1 diabetes. ${ }^{1}$ In Type 1 diabetes, an individual's autoimmune system destroys the insulin-secreting pancreatic $\beta$ cells, which reside in the Islets of Langerhans. ${ }^{2,3}$ Once the $\beta$ cells are destroyed, the pancreas no longer produces insulin, which is a vital hormone responsible for maintenance of blood glucose levels. ${ }^{3}$ Insulin is needed for intracellular transport of glucose into various tissues (e.g., muscle, adipose), which allows for the creation and storage of glycogen for use as an energy source for muscle contraction. ${ }^{3}$ In order for efficient synthesis and storage of glycogen in muscle tissue, blood glucose levels need to be controlled through readily available insulin. ${ }^{3}$

The ideal range of blood glucose levels is generally considered to be between 70 and $180 \mathrm{mg} / \mathrm{dl}^{4,5}$ In order to avoid hypo- and

Mason is with Graceland University, Lamoni, IA, USA. Russ, Tierney, and Mansell are with Temple University, Philadelphia, PA, USA. Mason (mason6@graceland. edu) is corresponding author. hyperglycemia, and stay in the ideal blood glucose range, individuals with Type 1 diabetes must balance physical activity, exercise, carbohydrate intake, and insulin administration. ${ }^{6}$ The response of blood glucose to physical activity and exercise are highly variable with intensity and duration. ${ }^{6}$ Moderate and vigorous exercise sessions increase the risk of hypoglycemia in individuals with Type 1 diabetes. ${ }^{7}$ Because of this, additional carbohydrate intake and/or reductions in insulin administration are required to maintain glucose levels in the ideal range. ${ }^{6}$ During exercise, an individual with Type 1 diabetes is responsible for making adjustments that will impact blood glucose levels. The individual must determine how intense and how long of an activity session they will undergo and adjust their insulin administration and/or carbohydrate intake accordingly. ${ }^{6}$ Because individuals with Type 1 diabetes selfadminister insulin through injections, pens, and insulin pumps, there is a potential for error that impacts blood glucose levels, glycogen synthesis, and storage. ${ }^{6}$ Eliminating individual modifications to insulin administration takes human error out of the blood glucose equation. ${ }^{6}$

The closed-loop control system, which eliminates the individual making insulin adjustments, was first approved by the U.S. Food and Drug Administration in 2016. ${ }^{8}$ Closed-loop control 
systems, also known as an artificial pancreas, use a combination of the insulin pump and continuous glucose monitor to control blood glucose. Unlike any previous method, in the closed-loop control system, the insulin pump responds automatically to changes in blood glucose readings and adjusts insulin administration accordingly to keep blood glucose levels within a preestablished goal. ${ }^{9}$ If blood glucose is rising above preset blood glucose limits, the pump will increase insulin delivery based on algorithms implemented by the treating health care team. If blood glucose is decreasing below preset blood glucose limits, the insulin pump will halt insulin delivery to avoid hypoglycemia. Similar to the pancreas, the closed-loop control system reacts to blood glucose fluctuations automatically, reducing human error. ${ }^{9}$ For the individual with Type 1 diabetes who exercises, the closed-loop control system has the potential to keep blood glucose levels better regulated.

\section{Focused Clinical Question}

In adolescents with Type 1 diabetes who participate in exercise, does a closed-loop control system versus a conventional insulin delivery system increase blood glucose time in the "ideal range"?

\section{Search Strategy}

A search of PubMed was conducted in June of 2020 using a PICO strategy to evaluate the question.

- Patient/client group: adolescents with Type 1 diabetes who exercise

- Intervention/assessment: closed-loop control system

- Comparison: open-loop control system

- Outcome: percentage time in the ideal blood glucose range of $70-180 \mathrm{mg} / \mathrm{dl}$

In addition, the following Boolean phrases were used:

- Closed-loop control system OR artificial pancreas

- Closed-loop control system AND Type 1 diabetes AND exercise AND adolescents

- Artificial pancreas AND glucose prediction AND exercise

\section{Inclusion Criteria}

- Studies that included open- and closed-loop control systems during exercise

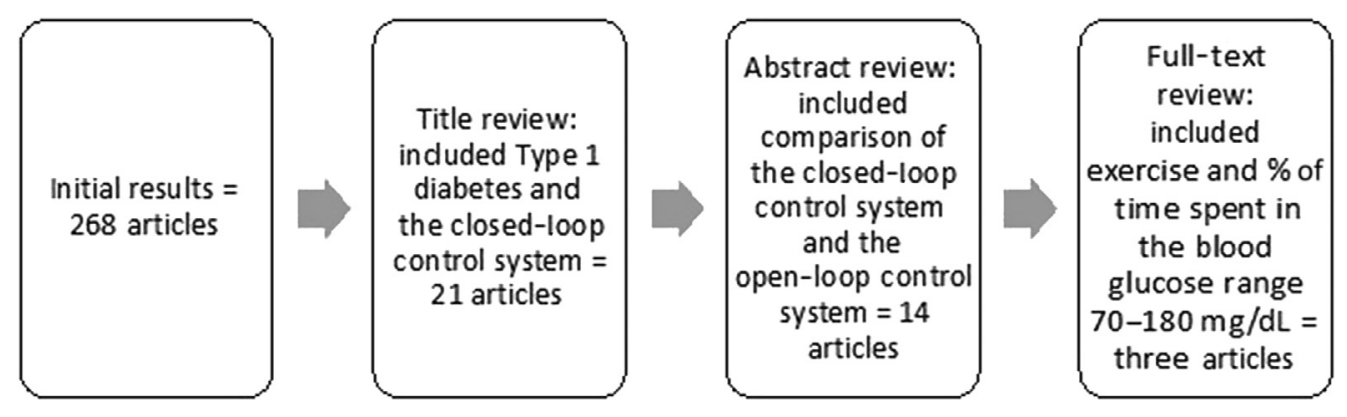

- Studies that included the outcome measure of percentage of time spent in the blood glucose range of $70-180 \mathrm{mg} / \mathrm{dl}$

- Studies that included adolescents

\section{Exclusion Criteria}

- Did not include comparison between open- and closed-loop control systems

- Did not include exercise

\section{Evidence Quality Assessment}

The Physiotherapy Evidence Database scale was used to critically appraise each article. ${ }^{10}$ The Physiotherapy Evidence Database scale assesses the methodological quality of research by scoring 10 items as present (1) or absent (0). ${ }^{10}$

\section{Results of Search: Summary of Search, "Best Evidence" Appraised, and Key Findings}

In total, this search yielded 268 records from PubMed. Each title was reviewed for inclusion of Type 1 diabetes and the closed-loop control system, resulting in 21 relevant articles. The abstract for each article was then assessed for a comparison between the closed-loop control system and an open-loop control system, which yielded 14 articles. Finally, the full text was analyzed, and three articles met the inclusionary criteria and were free from exclusionary factors (Figure 1). All three articles showed significant improvement in percentage of time in the blood glucose ideal range in the closed-loop control system versus the open-loop control system with exercise. ${ }^{4,5,11}$

\section{Results of Evidence Quality Assessment}

All three articles included in this critically appraised topic had a level of evidence of 1 . The Breton et al. ${ }^{4}$ and Ekhalaspour et al. ${ }^{11}$ articles were both randomized controlled trials that scored $9 / 10$ on Physiotherapy Evidence Database scale. The randomized, two-arm crossover clinical trial by Dove et al. ${ }^{5}$ also scored 9/10. All three studies included randomly allocated groups that were similar at baseline and reported statistical comparisons and point measures for a key outcome. A point was deducted for each study based on a lack of blinding of the subjects and researchers in order to keep the patients safe.

Figure 1 - Search results. 


\section{Clinical Bottom Line: Strength of Recommendation}

There is significant evidence supporting that the closed-loop control system keeps blood glucose in the ideal range for a higher percentage of time with exercise than an open-loop control system. Confidence intervals and effect sizes were figured using data (mean, median, $S D$, and sample size) provided by each article (Table 1). The Breton et al.' $\mathrm{s}^{4}$ article showed a moderate effect size (Cohen's $D$ ) of 0.4 , while the Dovc et al. ${ }^{5}$ and Ekhalaspour et al. ${ }^{11}$ showed large effect sizes of 1.2 each. The $95 \%$ confidence intervals were calculated for all three studies using the mean, $S D$, and number of participants. The confidence intervals for the Dovc et al. ${ }^{5}$ and Ekhalaspour et al.' ${ }^{11}$ articles did not intersect, revealing a statistically significant difference between the closed- and open-loop systems (Figure 2). The Breton et al. ${ }^{4}$ confidence intervals did intersect, but revealed that there was still a difference between the two groups (Figure 1). Percentage of time in the ideal range increased in the Breton study from $64.7 \%$ to $71.3 \%$, increased in the Dove study from $68.7 \%$ to $84.1 \%$, and increased in the Ekhalaspour study from $50 \%$ to $73.5 \%$.
In adolescents with Type 1 diabetes, $5 \%$ improvement in mean time in the ideal range results in clinically significant benefits. ${ }^{12,13}$ The Strength of Recommendation Taxonomy grade for this research is A.

\section{Implications for Practice, Education, and Future Research}

While many people with Type 1 diabetes use traditional insulin delivery systems (e.g., insulin shots, insulin pens, and insulin pumps), the potential for human error may make physically active patients vulnerable to dangerous blood glucose levels. Because of this, the closed-loop control system can be beneficial to athletes with Type 1 diabetes. Based on the results of this critically appraised topic, there is evidence to suggest that with exercise, the closed-loop control system kept blood glucose levels in the ideal range for longer periods of time than the open-loop control system. ${ }^{4,5,11}$

For the athlete with Type 1 diabetes, increased time in the ideal blood glucose range can positively impact training and competition. Moderate and vigorous exercise increases the risk of hypoglycemia during training, overnight, and the next day in individuals with

\section{Table 1 Summary Data}

\begin{tabular}{|c|c|c|c|}
\hline Author(s) & Breton et al. ${ }^{4}$ & Dovc et al. ${ }^{5}$ & Ekhalaspour et al. ${ }^{11}$ \\
\hline Study title & $\begin{array}{l}\text { Closed-loop control during intense pro- } \\
\text { longed outdoor exercise in adolescents } \\
\text { with type } 1 \text { diabetes: The artificial pancreas } \\
\text { ski study }\end{array}$ & $\begin{array}{l}\text { Closed-loop glucose control in young } \\
\text { people with type } 1 \text { diabetes during and after } \\
\text { unannounced physical activity: A ran- } \\
\text { domized controlled crossover trial }\end{array}$ & $\begin{array}{l}\text { Closed loop control in adolescents and } \\
\text { children during winter sports: Use of the } \\
\text { tandem control-IQ AP system }\end{array}$ \\
\hline $\begin{array}{l}\text { Study } \\
\text { participants }\end{array}$ & $\begin{array}{l}32(15 \mathrm{~F} \text { and } 17 \mathrm{M}) \text { adolescents with } \\
\text { Type } 1 \text { diabetes } \\
\text { Age }=10-16 ; \text { mean age }=13.2 ; \text { diabetes } \\
\text { duration in mean years }=6.9 \text { years } \mathrm{HbA}_{1 \mathrm{c}} \\
\text { mean }=8.5 \%\end{array}$ & $\begin{array}{l}20(\text { nine } \mathrm{F} \text { and } 11 \mathrm{M}) \text { adolescents with } \\
\text { Type } 1 \text { diabetes } \\
\text { Age }=10-17 ; \text { mean age }=14.2( \pm 2.0) \text {; } \\
\text { diabetes duration in mean years }=8.3 \\
( \pm 3.2) ; \mathrm{HbA}_{1 \mathrm{c}} \text { mean }=7.7 \%( \pm 0.6)\end{array}$ & $\begin{array}{l}48(24 \mathrm{~F} \text { and } 24 \mathrm{M}) \text { school aged children } \\
\text { and adolescents with Type } 1 \text { diabetes } \\
\text { Age }=7-17 ; \text { mean age }=12.3 ; \text { diabetes } \\
\text { duration in mean years }=5.4 ; \mathrm{HbA}_{1 \mathrm{c}} \\
\text { mean }=7.8 \%\end{array}$ \\
\hline $\begin{array}{l}\text { Inclusion/ } \\
\text { exclusion } \\
\text { criteria }\end{array}$ & $\begin{array}{l}\text { Inclusion criteria: Insulin-treated Type } 1 \\
\text { diabetes for greater than } 1 \text { year and insulin } \\
\text { pump use greater than } 3 \text { months. } \\
\text { Exclusion criteria: Recent history of severe } \\
\text { hypoglycemia or diabetes ketoacidosis } \\
\text { within the last } 6 \text { months, pregnancy, or } \\
\text { conditions incompatible with the practice } \\
\text { of winter sports in altitude. }\end{array}$ & $\begin{array}{l}\text { Inclusion criteria: Age } 10-17 \text { years, at least } \\
1 \text { year since Type } 1 \text { diabetes diagnosis, at } \\
\text { least } 3 \text { months of current use of an insulin } \\
\text { pump, HbA } \mathrm{HC}_{1 \mathrm{C}} \text { below } 9.0 \% \text {, BMI within } \\
\text { normal range, and absence of other medical } \\
\text { conditions. } \\
\text { Exclusion criteria: Concomitant diseases } \\
\text { that could influence control or compromise } \\
\text { safety, hypoglycemia unawareness, more } \\
\text { than two episodes of severe hypoglycemia } \\
\text { with seizure and/or coma within the pre- } \\
\text { vious } 6 \text { months, or history of one or more } \\
\text { episodes of diabetic ketoacidosis requiring } \\
\text { hospitalization within a month. }\end{array}$ & $\begin{array}{l}\text { Inclusion criteria: Age } 6-18 \text { years, Type } 1 \\
\text { diabetes diagnosis, insulin treated for at } \\
\text { least } 1 \text { year, and using an insulin pump for } \\
\text { at least } 3 \text { months. } \\
\text { Exclusion criteria: Recent history of severe } \\
\text { hypoglycemia or diabetes ketoacidosis } \\
\text { within the last } 6 \text { months, requiring long } \\
\text { acting or any on insulin antidiabetic } \\
\text { medications, pregnancy, active renal or } \\
\text { cardiac illness, or history of altitude } \\
\text { sickness. }\end{array}$ \\
\hline $\begin{array}{l}\text { Outcome } \\
\text { measures }\end{array}$ & $\begin{array}{l}\text { Collected: Percentage of time spent } \\
\text { within the blood glucose target range of } \\
70-180 \mathrm{mg} / \mathrm{dl}\end{array}$ & $\begin{array}{l}\text { Collected: Percentage of time spent } \\
\text { within the blood glucose target range of } \\
70-180 \mathrm{mg} / \mathrm{dl}\end{array}$ & $\begin{array}{l}\text { Collected: Percentage of time spent } \\
\text { within the blood glucose target range of } \\
70-180 \mathrm{mg} / \mathrm{dl}\end{array}$ \\
\hline Results & $\begin{array}{l}N=32,16 \text { per group } \\
\text { Mean time in target range and } S D \text { : } \\
\text { open loop } 64.7 \%( \pm 13.3), \\
\text { closed-loop control: } 71.3 \%( \pm 17.6) \\
\text { CI: OL [58.1, 71.4], } \\
\text { closed-loop control }[62.5,80.1] \\
\text { Cohen's } D=0.4 \\
p=.008\end{array}$ & $\begin{array}{l}N=20 \\
\text { Mean time in target range and } S D \text { : } \\
\text { open loop } 68.7( \pm 13.9), \\
\text { closed-loop control } 84.1( \pm 11.5) \\
\text { CI: open loop }[62.5,74.9] \\
\text { closed-loop control }[79.0,89.2] \\
\text { Cohen's } D=1.2 \\
p=.0057\end{array}$ & $\begin{array}{l}N=48,24 \text { per group } \\
\text { Mean time in target range and } S D \text { : } \\
\text { open loop } 50 \%( \pm 26.8), \\
\text { closed-loop control } 73.5 \%( \pm 8.4) \\
\text { CI: open loop }[39.1,60.9], \\
\text { closed-loop control }[70.1,76.9] \\
\text { Cohen's } D=1.2 \\
p=.01\end{array}$ \\
\hline $\begin{array}{l}\text { Evidence } \\
\text { quality }\end{array}$ & $\begin{array}{l}\text { SORT: } 1 \\
\text { PEDro: } 9 / 10\end{array}$ & $\begin{array}{l}\text { SORT: } 1 \\
\text { PEDro: } 9 / 10\end{array}$ & $\begin{array}{l}\text { SORT: } 1 \\
\text { PEDro: } 9 / 10\end{array}$ \\
\hline $\begin{array}{l}\text { Support for } \\
\text { the answer }\end{array}$ & Yes & Yes & Yes \\
\hline
\end{tabular}

Note. $\mathrm{BMI}=$ body mass index $; \mathrm{F}=$ female; $\mathrm{M}=$ male; $\mathrm{PEDro}=$ Physiotherapy Evidence Database scale $\mathrm{CI}=$ confidence interval; $\mathrm{Hb} \mathrm{A}_{1 \mathrm{c}}=$ hemoglobin $\mathrm{A} 1 \mathrm{c}$. 


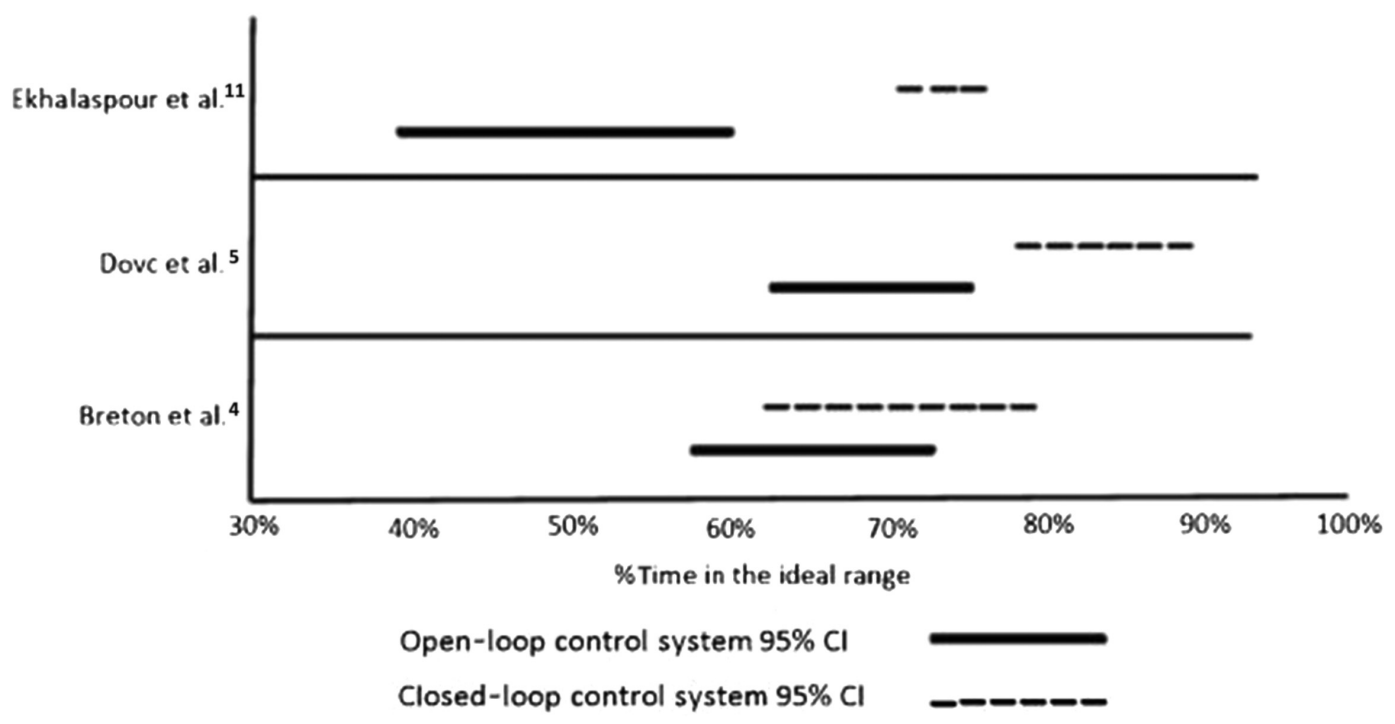

Figure 2 - Confidence intervals for time in ideal range. $\mathrm{CI}=$ confidence interval.

diabetes. ${ }^{7}$ Hypoglycemic episodes would mean having to stop training or leave the competition in order to ingest carbohydrates to increase blood glucose levels. By using the closed-loop control system, which keeps blood glucose levels in the ideal range for longer periods of time, athletes with Type 1 diabetes can continue to train and compete without interruption due to dangerous fluctuations in blood glucose levels. In addition, working in an ideal blood glucose range helps their body function more efficiently. ${ }^{14}$ High blood glucose levels change energy and protein metabolism during exercise. ${ }^{14}$ When blood glucose levels are high, energy expenditure is increased for the same workload. ${ }^{14}$ In other words, when blood glucose is high, the athlete must expend much more energy to get the same result as their counterparts who have ideal blood glucose levels. This can have an adverse effect on both training and competition. Keeping blood glucose levels in the ideal range positively affects the athlete with Type 1 diabetes.

While the included research is high quality, the amount of research in this area is limited. The closed-loop control system is a new technology and has not been researched on a large number of subjects. Specifically, there is little research in regards to exercise and the closed-loop control system.

Future research is needed on the closed-loop control system with larger populations of physically active individuals with Type 1 diabetes. Research on the closed-loop system should focus on specific energy systems being utilized and the effect of the closedloop system on those systems (e.g., anaerobic activity vs. aerobic activity). By focusing on specific energy systems, application to individual sports can be identified.

\section{CAT Kill Date: September 2023}

CATs have limited life and should be revisited approximately 2 years after publication (see https://doi.org/10.1123/ijatt.2018-0093).

\section{References}

1. Centers for Disease Control and Prevention. National Diabetes Statistics Report. Atlanta, GA: Centers for Disease Control and Prevention, U.S. Department of Health and Human Services; 2020. https://www.cdc.gov/diabetes/pdfs/data/statistics/national-diabetesstatistics-report.pdf. Accessed September 4, 2020.
2. Atkinson MA, Eisenbarth GS, Michels AW. Type 1 diabetes. Lancet. 2014;383(9911):1-4. doi:10.1016/S0140-6736(13)60591-7

3. Wilcox G. Insulin and insulin resistance. Clin Biochem Rev. 2005; 26(2):19-39. PubMed ID: 16278749

4. Breton MD, Chernavvsky DR, Forlenza GP, et al. Closed-loop control during intense prolonged outdoor exercise in adolescents with type 1 diabetes: the artificial pancreas ski study. Diabetes Care. 2017;40(12):1644-1650. doi:10.2337/dc17-0883

5. Dovc K, Macedoni M, Bratina N, et al. Closed-loop glucose control in young people with type 1 diabetes during and after unannounced physical activity: a randomised controlled crossover trial. Diabetologia. 2017;60(11):2157-2167. doi:10.1007/s00125-017-4395-z

6. Colberg SR, Laan R, Dassau E, et al. Physical activity and type 1 diabetes: time for a rewire? J Diabetes Sci Technol. 2015;9(3): 609-618. doi:10.1177/1932296814566231

7. Metcalf KM, Singhvi A, Tsalikian E, et al. Effects of moderate-tovigorous intensity physical activity on overnight and next-day hypoglycemia in active adolescents with type 1 diabetes. Diabetes Care. 2014;37(5):1272-1278. doi:10.2337/dc13-1973

8. Innovation Milestones. Medtronic. https://www.medtronicdiabetes.com/ about-medtronic-innovation/milestone-timeline. Accessed April 21, 2020.

9. Farmer TG, Edgar TF, Peppas NA. The future of open and closedloop insulin delivery for diabetes mellitus. J Pharm Pharmacol. 2008; 60(1):1-13. doi:10.1211/jpp.60.1.0001

10. de Morton NA. The PEDro scale is a valid measure of the methodological quality of clinical trials: a demographic study. Aust J Physiother. 2009;55(2):129-133. doi:10.1016/S0004-9514(09)70043-1

11. Ekhalaspour L, Forlenza GP, Chernavvsky D, et al. Closed loop control in adolescents and children during winter sports: use of the tandem control-IQ AP system. Pediatr Diabetes. 2019;20(6): 759-768. doi:10.1111/pedi.12867

12. Beck RW, Bergenstal RM, Cheng P, et al. The relationships between time in range, hyperglycemia metrics, and HbA1c. J Diabetes Sci Technol. 2019;13(4):614-626. PubMed ID: 30636519 doi:10.1177/ 1932296818822496

13. Vigersky RA, McMahon C. The relationship of hemoglobin A1C to time-in-range in patients with diabetes. Diabetes Technol Ther. 2019; 21(2):81-85. doi:10.1089/dia.2018.0310

14. Hebert SL, Nair KS. Protein and energy metabolism in type 1 diabetes. Clin Nutr. 2010;29(1):13-17. doi:10.1016/j.clnu.2009.09.001 